\title{
The Benefits of a Near-peer Mentoring Experience on STEM Persistence in Education and Careers: A 2004-2015 Study
}

\author{
Margery K. Anderson ${ }^{1}$, R. Jerome Anderson ${ }^{1}$, Laura S. Tenenbaum¹, Emily D. Kuehn', Holly K. M. Brown ${ }^{1}$, Swati B. $^{1}$ \\ Ramadorai $^{1}$, and Debra L. Yourick ${ }^{1}$
}

${ }^{1}$ Department of Science Education and Strategic Communications, Walter Reed Army Institute of Research, 503 Robert Grant Avenue, Silver Spring, MD 20910.

Keywords: Mentors, URE, longitudinal, persistence, careers

Publication Date: January 2, 2019

DOI: https://doi.org/10.15695/jstem/v2i1.01

\begin{abstract}
This retrospective study, from 2004 to 2015, explored the career trajectories of undergraduates and recent post-baccalaureates who participated in an undergraduate research experience (URE) that combined both laboratory experience and mentoring younger students. Forty former interns completed an online survey focusing on their path from internship to career. Interns were queried about the skills they perceived as being critical in their subsequent STEM-related endeavors. They also wrote narratives that indicated their attitudes about STEM education, outreach and mentoring. The responses showed all but one of the 40 participants were engaged in either STEM-related careers or education. The participants provided examples of what aspects of the internship had long-term impact on their persistence in the sciences. As the majority of the respondents were from populations traditionally underrepresented in STEM careers, this study adds to the literature on the positive effect of internships on individual STEM persistence. The results indicated that this internship helped create a cadre of professionals who not only persisted in STEM but also retained an active commitment to helping younger students gain an appreciation for science. It was concluded that undergraduate persistence in the sciences is strengthened when interns are given training in and the responsibility for mentoring.
\end{abstract}

\section{INTRODUCTION}

The necessity of undergraduate research experiences (UREs) for students in science, technology, engineering and mathematics (STEM), and science education, is well-established in the literature (Dolan and Johnson, 2009; Hayward et al., 2017; Hamos et al., 2009; National Academies of Sciences, Engineering, and Medicine, 2017). Although there are variations on traditional dyadic mentoring, in the typical STEM-URE, the student is considered an apprentice with few opportunities to share knowledge. With funding from the National Institutes of Health through Science Education Partnership Awards (NIH-SEPA), the Walter Reed Army Institute of Research (WRAIR) originated and developed a model summer URE that allowed undergraduate students or recent graduates to mentor slightly younger students who are part of the middle/high school Gains in the Education of Mathematics and Science (GEMS) program (Jett et al., 2005). This model, called the near-peer mentor (NPM) model, has been shown to provide benefits similar to those of a traditional, laboratory-focused URE (Anderson et al., 2015).

Here we report our finding on assessing whether there were any long-term contributions of the internship to the NPMs' careers and persistence in STEM. From 2004 to 2015, approximately 241 NPMs participated in a combined science and education summer internship at the WRAIR. Given this relatively large data resource, in 2016 the WRAIR educational program administrators designed a retrospective survey of previous near-peer mentors. The study was designed to answer three questions:

1. In the years following the near-peer mentoring, what percentage of the near-peer mentors continued in STEM-related careers or educational advancement?

2. What skills or abilities did the near-peer mentors consistently report as being influential in obtaining a subsequent teaching opportunity, research internship, or employment?

3. How did the near-peer mentor experience shape their attitudes, beliefs, and decisions about STEM careers, education, and outreach?

\section{PROGRAM OVERVIEW}

Since the late 1990s, undergraduates and recent post-baccalaureates at the WRAIR have participated in a unique internship that combines access to WRAIR laboratories and sharing laboratory practices with slightly younger students (Anderson et al., 2015). In the initial years of this study, the NPMs worked in WRAIR laboratories part-time and taught 
part-time. As the GEMS program enrollment blossomed, the focus of NPM responsibilities shifted to science education and, most importantly, working with individual mentors to complete an original laboratory module of their choice.

A NPM experienced both sides of the mentor-mentee relationship; they were mentored as science interns while concurrently mentoring their own mentees in the GEMS teaching laboratory. This required the undergraduates to demonstrate a range of technical and communication skills. Applicants were personally interviewed by the GEMS educational team and selected based on their strengths in four areas: (1) previous laboratory experiences; (2) a willingness to focus on science education research and curriculum development; (3) prior mentoring and community service; and (4) past experience demonstrating interpersonal competencies with adolescents, professional educators, and research scientists. An average of 18 NPMs participated each year of the study period. The number fluctuated to maintain a mentor-mentee ratio of 1:6 in the laboratory teaching program. The interns represented a wide variety of STEM-related majors including physical and life sciences, engineering, math, science education, and computer science. The mentors received a living stipend, presented their research at the Institute's annual poster session, and networked with bench researchers through seminars and brown-bag lunches. Notably, all NPMs completed a National Agency Clearance Investigation (NACI) and received an initial clearance that qualified them for Department of Defense laboratories internships and entry-level employment.

The applicants were representative of the diverse ethnic and racial populations that compose the Washington, D.C metropolitan region. Since beginning formal records of NPM demographic information in 2013, 49\% of NPMs who reported their racial or ethnic backgrounds have identified with groups that are underrepresented in STEM and $57 \%$ identified as female. While the program does not track the socioeconomic status of NPMs, it purposefully offers a competitive stipend drawn from educational grants to make the internship accessible to applicants without adequate economic means, as unpaid (and underpaid) internships are a major structural barrier to STEM-related careers (Curiale, 2010).

To prepare NPMs for mentoring slightly younger STEM students, they received two weeks of training from licensed educators, researchers, and subject matter experts (Anderson et al., 2015). Initially the training focused on lesson plans, ethics and law, laboratory safety practices, general classroom management strategies, biomedical research techniques, and engineering design to assure competency in relevant skills. Over the years, the training was expanded to include designing independent learning opportunities, curriculum development, evaluations, diversity training, theories of learning, and a variety of pedagogical practices shown to be effec- tive with adolescents. There were weekly meetings with the NPMs to discuss pedagogy, challenges, laboratory protocols, and the continued development of professional skills such as writing abstracts, interviews, and resumes.

From its beginning the NPM paradigm was unique in that the undergraduate NPMs were given almost full responsibility for development and implementation of the modules to be taught to the GEMS student participants. While they were guided by, and needed final approval from, the educational supervisors, it was the NPMs who developed the laboratory protocols based on past experiences and discussions with researchers. They set the curriculum, made the daily schedules, did their own preparation, piloted the modules, managed the participants, wrote the lesson plans, oversaw safety, ordered supplies, cared for laboratory animals, and maintained organization in the teaching laboratory. Researchers were always available to offer support, constructive criticism, or a listening ear, but every effort was made to allow the mentors and participants to form a STEM learning community (Tenenbaum et al., 2014). Over the years, numerous mentors have presented their original modules at undergraduate forums and some have even published (e.g. Bliss et al., 2007; Morales et al., 2017).

Taught by NPMs using the modules the NPMs had developed, the GEMS students were given a science immersion experience that introduced them to multiple aspects of biomedical science and engineering. Over the years of this study, the 4742 GEMS students were primarily from underserved and underrepresented populations in STEM disciplines. Annually, 50\% were female and 60\% - 70\% identified with a traditional minority population or as a first generation student in this country (internal records). During each of ten sequential, one or two-week-long GEMS sessions, different age groups of students (beginning, grades 7-8; intermediate, grades 9-10; advanced, grades 11-12) received laboratory-centered instruction from the NPMs. In the mornings, GEMS students completed NPM facilitated experiments suited for the age group. In the afternoons, while the younger students continued guided investigations, the older students began a week(s) long project. Older students chose from a range of project topics that were pre-selected by the mentors and educational team. The NPMs facilitated the projects and acted as subject matter experts. GEMS students established a strong rapport with their NPMs, their projects, and each other. This combination contributed to the positive narratives and persistence of GEMS students (Tenenbaum et al., 2017).

\section{LITERATURE REVIEW}

There are numerous theoretical models that focus on mentoring relationships that concurrently promote academic, psychosocial, and career advancement (Crisp et al., 2017). Among these theories, the NPM internship draws primarily 
upon outcomes-based and experiential frameworks (Carraccio et al., 2017). These assume that properly designed and implemented experiences can and do impact learning in the STEM disciplines (Wu et al., 2017). As reported by the National Academies of Sciences, Engineering, and Medicine (2017), UREs are experiential, and they facilitate scientific learning in ways STEM coursework and even inquiry-based classes do not. A laboratory experience allows

. . students [to] learn by engaging in plan-
ning, experimentation, evaluation, interpretation,
and communication of data and other results in
light of what is already known about the question
of interest. They can pose relevant questions that
can be solved only through investigative or design
efforts-individually or in teams-and attempt to
answer these questions despite the challenges,
setbacks, and ambiguity of the process and the re-
sults obtained (p. 214).

As indicated in the Program Overview, above, the NPM internship was specifically designed to allow this sequence of "planning, experimentation, evaluation, interpretation, and communication of data and other results" so the interns could gain greater insight into the scientific enterprise. (Merriam et al., 2007; Stirling et al., 2017). The NPMs developed laboratory modules based on current WRAIR research and essential laboratory skills. They then shared their learning, experiences and growing knowledge with younger students as they guided them through the basics of laboratory research. Thus, near-peer mentoring integrated the undergraduates into a cycle of learning and teaching, being mentored and mentoring, with one reinforcing the other.

A mentor's impact on both undergraduates' and high school students' intentions to persist in their education and engage in STEM careers has been well documented (Eagan et al., 2013; Ghee et al., 2016; Linn et al., 2015; Weston and Laursen, 2015; Wang, 2013). Representative of the literature is a meta-study by Adedokun et al. (2013). The authors studied 156 undergraduates in a university-based URE designed to deepen their interest in further STEM study and aspirations for STEM careers. The study showed the URE had a positive effect on the career aspirations of students.

Literature on URE students' actual persistence in STEM is more limited. From aspiration for graduate study to matriculation, Bascom-Slack et al. (2012) studied a URE course taught at a research university and reported that the matriculation rate into doctoral programs was three times greater for those with a URE than for those who did not participate. Moving from the educational perspective of participation to engagement, a study by Hanauer et al. (2012) used linguistic analysis tools to ascertain the degree to which students in three different types of laboratory experiences took ownership of the assigned projects. While the purpose of the study was not to investigate the long-term effects of the UREs on the students, the researchers did have access to data on the progression of students four years after the study. They found that $88 \%$ of the students who had engaged in the most rigorous laboratory experience had persisted in science, either in education or in a career, while $69 \%$ of the students who had been involved in a less intense URE persisted in science. The researchers concluded that students who chose increased project ownership, directly related to the intensity of the research experience, led to greater "long-term persistence in the sciences" (Hanauer and Dolan, 2014).

While NPMs receive the academic, psychosocial, and career promotion benefits of being mentored (Anderson et al., 2015), their internship is unique in that it formally incorporates undergraduates as mentors into its design. Thus, in addition to receiving the benefits of a typical URE, the near-peer mentors experience the responsibilities of mentoring others. They have ownership of their laboratory modules and the responsibility to communicate them to the slightly younger students. The literature on the benefits of mentoring to mentors is thus useful in this context because it will help elucidate the benefits the NPMs may receive from their mentoring URE experience.

In a program similar to the near-peer mentorship at the WRAIR, the Nebraska Science, Technology, Engineering and Math 4U (NE STEM 4U) program recruits undergraduates to mentor public school students in STEM subjects (Nelson and Cutucache, 2017). Seven of the undergraduate mentors were interviewed to ascertain the benefits they gained from the program. The undergraduate mentors reported greater understanding of, and ability to explain, scientific concepts and better critical thinking and problem-solving skills. They also felt mentoring helped them clarify career options. The conclusions reached regarding the Nebraska program were supported by other research that indicated mentoring opportunities within the community prove beneficial for students throughout their schooling (Hazari et al., 2017; Russell et al., 2007).

A study that included analysis of both the students' experiences and the advisors' view of the URE was conducted by Hayward et al. (2017) at a large research university. As was true of a similar study (Dolan and Johnson, 2009), the research advisors, who were primarily graduate students and post-doctoral researchers, all reported increased productivity in their laboratories because of the presence of the undergraduate researchers. They also reported increased understanding of science concepts because they taught those concepts to others. Both groups reported feelings of personal satisfaction as they saw students gain scientific knowledge and laboratory skills. They found mentoring important to the furtherance of their own careers, just as the undergraduate mentors in the NE STEM $4 \mathrm{U}$ program found mentoring helped clarify their career alternatives. 
As a final example of the cycle of mentoring, Laursen et al. (2010) authored a comprehensive study of undergraduate research in STEM fields. Their work was based on several related studies, including a four-college study of undergraduate researchers and faculty mentors. One goal of that study was to ascertain the benefits received by the mentors. Faculty mentors appreciated the creativity of the undergraduates in their suggestions to pursue novel lines of research and the additional work the faculty were able to accomplish because of their mentees. Mentoring helped some faculty attain tenure. Intrinsic benefits included the feelings of satisfaction from seeing students learn and grow and praise from colleagues as the well-trained undergraduates continued their work in graduate school.

The benefits of being a mentor are consistent, regardless of the age or experience level of the mentor. Mentors directly responsible for scientific research found undergraduate mentees to be helpful, if not essential, for increased productivity and creative insights into the laboratory work (Hayward et al., 2017; Reid et al., 2016). Across all the studies, mentors found mentoring beneficial for their careers, as is true for mentoring generally (Allen, 2007). But beyond these instrumental benefits, mentors consistently found their ability to teach science increase, their communication skills improve, and their understanding of scientific concepts sharpen. They also found emotional benefits from the friendships they developed and the interactions they had within the laboratory (Hayward et al., 2017). Many, if not all, of the benefits described in the studies cited will be seen in reports of mentor benefits received by the NPMs as they made decisions concerning their careers.

\section{METHODOLOGY}

During the twelve-year study period, the summer programs were consistent within the WRAIR laboratories with respect to the program structure and goals, thus allowing the NPM experience to be comparable across the years. This relative uniformity of experience made the NPMs a unique population for exploring the impact of this internship on persistence in the STEM disciplines and how the internship contributed to that persistence.

The survey instrument was prepared by three of the authors with questions based on previous program evaluations that asked NPMs about the internship and their career aspirations. The Survey Gizmo platform was used to administer the survey (www.surveygizmo.com). Because the survey was intended for previous NPMs for whom email addresses were available, the survey may be described as an "internet survey of specifically-named persons" (American Association for Public Opinion Research, 2015) or a "list-based sample" survey (Couper and Bosnjak, 2010). Therefore, no sampling was done and invitations were emailed to the 150
NPMs for whom email addresses were available. The survey was open from May through August 2016. Two reminders were sent to non-responders.

Completed questionnaires were received from 40 NPMs of the 121 for whom the program had working email addresses. The response rate was calculated according to the formula presented by Kalton (1983), which is the number of completed questionnaires divided by the number of eligible persons in the sample (or, in this case, the population). Discounting those with non-working email addresses, the response rate is $33 \%$, which compares favorably with other surveys of named persons (Keusch, 2012; Petrovčič et al., 2016). Table 1 shows the distribution of responses. The eight partially completed questionnaires were not included in the analysis.

Table 1. Distribution of Responses

\begin{tabular}{lc}
\hline Response & Number \\
\hline Completed questionnaires & 40 \\
Partially completed questionnaires & 8 \\
Email address returned as invalid & 29 \\
Explicit refusal & 1 \\
No response & 72 \\
\hline Total & 150 \\
\hline
\end{tabular}

Quantitative data from the survey (primarily categorical) were analyzed with spreadsheet software and the NCSS statistical package (NCSS, LLC, 2016). Qualitative data (narratives) from the survey were transferred from Survey Gizmo to ATLAS.ti 8.1, a qualitative data analysis and research program (ATLAS.ti Scientific Software Development GmbH, 2017). For each open-ended question, the responses were compiled. Three readers from within the research team and one external reviewer read all responses for all questions and identified themes. Using iterative cycles of deductive and inductive methodologies (Bogdan and Biklen, 2007), a coding manual was developed. To frame the pattern of themes identified in the narratives, two coding methods were selected: 1) descriptive coding, which summarizes the primary topic of the excerpts; and 2) values coding, which reflects the respondent's values, attitudes, beliefs, and decisions that represent his or her perspectives (Maio and Haddock, 2014; Saldana, 2015). The coding manual underwent three revisions until the coding team obtained an interrater reliability of $90 \%$, with remaining conflicts resolved by consensus coding.

Both open and closed-response questions were used to address the first research question concerning persistence in STEM-related careers or educational advancement. The second research question, the skills or abilities the NPMs reported as influential in obtaining a subsequent teaching opportunity, internship, or employment, was addressed through descriptive coding that assigned basic labels within the nar- 
ratives to provide an inventory of topics (Saldana, 2015). The third research question, which focused on how the near-peer mentor internship shaped their attitudes, beliefs, and values about STEM careers, education, and outreach, involved extensive coding across all narratives as the NPMs explained the reasons they made a decision, and how those decisions had impacted their education and careers. Upon completion of coding the final report of themes and quotations was generated by ATLAS.ti 8.1.

\section{RESULTS}

Portrait of Respondents. In terms of temporal distribution, NPMs from each year of the 12-year timeframe responded (Figure 1). As the survey was done in 2016, the mentors had one to eleven years to reflect on their experiences.

Table 2 shows the gender and racial profiles of the 40 respondents. As Table 2 indicates, $75 \%$ of the respondents were female. The largest category was Caucasian females at $13(32.5 \%)$, followed by Black/African American females at nine $(22.5 \%)$ and Asian females at seven $(17.5 \%)$.

In terms of geographical location, in 2016, most of the respondents $(55 \%)$ were concentrated in the Washington, D.C. to New York corridor. Only five respondents $(12.5 \%)$ within the U.S. were located west of the Mississippi River. Three

Figure 1. Respondents by year of internship

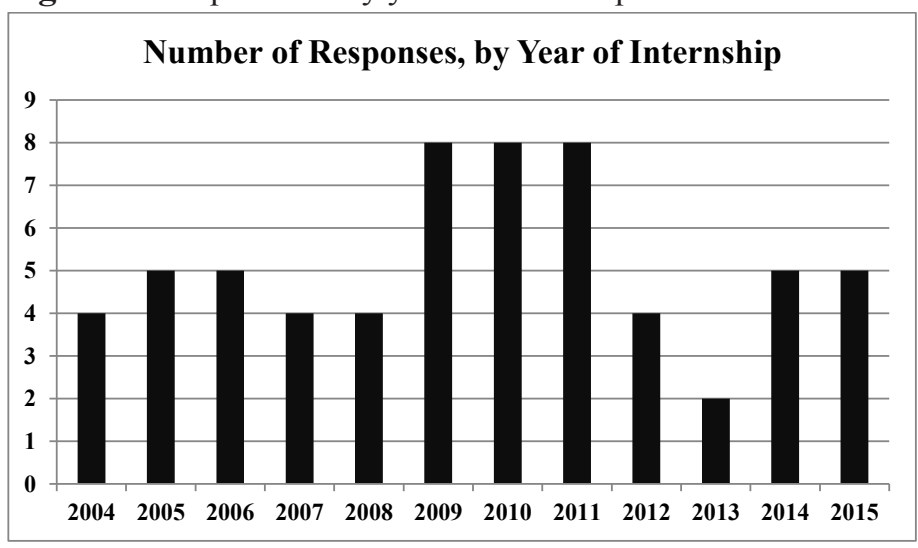

Table 2. Respondents by Gender and Race

\begin{tabular}{lcccc}
\hline \multicolumn{1}{c}{ Race } & $\begin{array}{c}\text { Choose not to } \\
\text { Respond }\end{array}$ & Female & Male & Total \\
\hline Asian & 0 & 7 & 2 & 9 \\
Black/African-American & 0 & 9 & 3 & 12 \\
Caucasian & 0 & 13 & 3 & 16 \\
Choose not to respond & 1 & 1 & 0 & 2 \\
Two or more races & 0 & 0 & 1 & 1 \\
\hline Total & 1 & 30 & 9 & 40 \\
\hline
\end{tabular}

respondents $(7.5 \%)$ were overseas; one each was in the United Kingdom, Germany, and the Philippines.

Research Question One. The first research question sought information about near-peer mentor continuity in STEM-related careers or educational studies. To trace the development from student to career, two separate questions were asked: 1) what was your placement after the final year of being a NPM and 2) what is your current placement.

As shown in Table 3, $21(52.5 \%)$ returned to their academic pursuits following their final year as a mentor. This included 12 students (30\%) who accepted a subsequent internship at another institution. Utilizing networking opportunities provided through the URE, $11(28 \%)$ NPMs accepted a subsequent internship at the WRAIR or sister institution. Finally, eight (20\%) of the respondents found career opportunities following their final WRAIR experience.

The participants were then asked about their current professional status. The results of the survey shown in Table 4 indicate that $19(47.5 \%)$ of the 40 respondents were in STEM or STEM-related careers while half of the former NPMs (20; $50 \%$ ) were in STEM-related educational pursuits. Only one of the former NPMs who responded to the survey was not in a STEM program (undergraduate or graduate) or in a STEM-related career.

Table 3. Following their final year as near-peer mentors, the interns pursued different options.

\begin{tabular}{lcc}
\hline & Post-NPM Positions \\
\hline Career & 8 & $20.00 \%$ \\
Subsequent UG internship & 12 & $30.00 \%$ \\
School -- Graduate & 8 & $20.00 \%$ \\
School -- UG & 1 & $2.50 \%$ \\
WRAIR/Other Gov't. & 11 & $27.50 \%$ \\
\hline Total & 40 & $100.00 \%$ \\
\hline
\end{tabular}

Table 4. Current Professional Status of Respondents

\begin{tabular}{lcc}
\hline Status & Count & Percent \\
\hline $\begin{array}{l}\text { Undergraduate (includes students on } \\
\text { internship) }\end{array}$ & 9 & $22.50 \%$ \\
Graduate/Medical School & 11 & $27.50 \%$ \\
Educator & 2 & $5.00 \%$ \\
Engineer & 3 & $7.50 \%$ \\
Homemaker & 1 & $2.50 \%$ \\
IT Professional & 3 & $7.50 \%$ \\
Medical Professional (MD, EMT, & 7 & $17.50 \%$ \\
Dentist, Administrator) & 4 & $10.00 \%$ \\
Other STEM-related Profession & 4 & \\
\hline
\end{tabular}


Nineteen $(47.5 \%)$ of the respondents are in STEM or STEM-related careers. The largest category is medical professionals (seven; $17.5 \%)$; three $(7.5 \%)$ former NPMs are engineers and another three $(7.5 \%)$ are IT professionals; two $(5.0 \%)$ of the former NPMs are educators. Four $(10 \%)$ of the former NPMs are classified as other STEM professionals. This category includes research chemists, a water quality modeler and one unspecified STEM professional. The only former NPM not in STEM has chosen to not work in the professional setting while her children are young. She noted in her response that she serves as a vocal advocate for elementary school science.

Of the $20(50 \%)$ respondents continuing their education, nine $(22.5 \%)$ were undergraduates, seven $(17.5 \%)$ were in graduate school and four $(10 \%)$ were in medical school. Two of the nine undergraduates majored in biology; the other majors included electrical or computer engineering, molecular genetics, forensic science, environmental sustainability, and global studies/global health. Of the seven students pursuing graduate studies, three selected the neurosciences, with the other students studying in fields ranging from agricultural engineering to chemical engineering to biological sciences. These results clearly show that the WRAIR NPMs who responded persisted in STEM-related activities, both as professionals and as students following their NPM internships.

Research Question Two. Research question two explored how the internship was influential in obtaining a subsequent teaching opportunity, research internship, or employment. The first survey question considered how the NPM experience shaped the respondents' current career paths, and the second addressed practical skills acquired through the internship, including networking. Table 5 summarizes these themes.

The former NPMs wrote detailed responses. Unexpectedly, the greatest number of NPM quotations (38 quotes, 95\%)

Table 5. Themes that emerged from Research Question 2

\begin{tabular}{lcc}
\hline Theme & $\begin{array}{c}\text { Number of } \\
\text { Respondents } \\
\text { Represented }\end{array}$ & $\begin{array}{c}\text { Percent of } \\
\text { Respondents } \\
\text { Represented }\end{array}$ \\
\hline $\begin{array}{l}\text { Currently engaged in mentoring } \\
\text { (full or part-time) }\end{array}$ & 38 & $95 \%$ \\
$\begin{array}{l}\text { Currently engaged in mentoring } \\
\text { (part-time only) }\end{array}$ & 18 & $45 \%$ \\
$\begin{array}{l}\text { NPM experience expanded my } \\
\text { scientific knowledge }\end{array}$ & 15 & $38 \%$ \\
$\begin{array}{l}\text { NPM experience gave me } \\
\text { specific career skills }\end{array}$ & 36 & $90 \%$ \\
$\begin{array}{l}\text { NPM experience gave me confidence/ } \\
\text { leadership skills }\end{array}$ & 12 & $30 \%$ \\
$\begin{array}{l}\text { NPM experience gave me } \\
\text { interpersonal skills that helped me in } \\
\text { the next step of my career or education }\end{array}$ & 40 & $100 \%$ \\
\hline
\end{tabular}

related not to the past but rather to their current teaching and mentoring activities. They reported having a range of related positions, from undergraduate teaching assistant to giving "mini-lectures to medical students as a resident physician." In addition, the financial practicality of mentoring skills was summarized by one participant who directly credited it with "numerous teaching/tutoring positions throughout college and grad school."

Even those not currently mentoring full time, (18 quotes; $45 \%$ ) wrote of their skills still being applicable to their present situations. One respondent wrote, "being a near-peer mentor allowed me to build on a lot of skills that I continue to use today. In my current position, I built on my ability [to] work in a team, as well as how to communicate more clearly and in an organized manner." These sentiments were echoed by others in phrases such as, "it helped give me confidence and experience in teaching and presenting scientific information to a general audience," and it "improved my confidence level in the areas of public speaking, personal independence, and teaching," and the internship "helped me to stay active....to better understand some of the same subjects I was discussing in a way that I could break it down into layman's terms."

The former NPMs referenced practical skills related to knowledge acquisition, professional networking and working within a bureaucracy, applying to graduate school, and obtaining employment. Expanded scientific knowledge was mentioned in fifteen responses (38\%). They also spoke of refining their career aspirations as "it helped me foster an interest in evolution" and "I got to explore different science fields in which I had little information." Thirty six of the 40 respondents $(90 \%)$ listed a specific career skill first gained or practiced as a NPM. They wrote that the NPM-URE was a "great application item" or about "learning to deal with difficult superiors." A common sub-theme was that "I grew in my self-confidence because of the program" or the internship "sharpened my leadership skills." In total, 12 quotations (30\%) specifically used the words confidence or leadership. As summarized by one respondent, the program "allowed me to practice self-confidence, communicate and understand various science fields, understand and use laboratory practices, and emphasized the bigger picture of science in the world and everyday life." Improved management and communication skills within a work setting was also a subject, with comments about learning to "take on a leadership role in the laboratory," "I learned effective management of my time and efforts and that of my colleagues as well," and " how to speak to an audience, and tailor my content to the audience." Lastly, the respondents referenced the networking opportunities built through this combined internship. The "references," "meeting teams of professionals," and "building effective and productive communication between the scientist and student" were critical for their academic and 
professional pursuits. All of the respondents stated that they applied these interpersonal skills to obtain their next position or academic placement.

Research Question Three. Research question three focused less on the skills and knowledge first acquired during the internship, and more on identifying the key components of the internship that the respondents associated with their career or educational decisions. All the narratives were explored for comments about attitudes, beliefs, and values related to perseverance, education, and outreach and how these impacted their decisions. The two-part survey question, how did being a near-peer mentor affect your interest

Table 6. Themes that emerged from Research Question 3

\begin{tabular}{lcc}
\hline Theme & $\begin{array}{c}\text { Number of } \\
\text { Respondents } \\
\text { Represented }\end{array}$ & $\begin{array}{c}\text { Percent of } \\
\text { Respondents } \\
\text { Represented }\end{array}$ \\
\hline $\begin{array}{l}\text { Positive attitude toward } \\
\text { mentoring to active mentoring }\end{array}$ & 38 & $95 \%$ \\
$\begin{array}{l}\text { NPM mentorship helped } \\
\text { clarify my own scientific } \\
\text { values }\end{array}$ & 17 & $42 \%$ \\
$\begin{array}{l}\text { NPM experience increased } \\
\text { my passion for science }\end{array}$ & 44 & $100 \%$ \\
\hline
\end{tabular}

in STEM education outreach and describe a recent outreach experience, prompted thoughtful reflections. These themes are summarized in Table 6.

Foremost, NPMs focused on how the experience changed their personal beliefs about STEM outreach. This was exemplified by the comment: "I have actively sought opportunities to become involved in science outreach." The former mentors report that their commitment began with positive memories of student interactions such as "seeing the students pick up and understand the concepts was truly rewarding," and the awareness that "I was able to play a role in other students' lives." From their present day perspective, 21 respondents $(52.5 \%)$ said the internship reinforced their belief in STEM outreach, while another 12 (28\%) said that the internship led them to become much more interested.

The transition from a generally positive attitude to a belief that led to continued action was evident in 38 responses $(95 \%)$ as participants specifically described their current outreach activities. One participant wrote, "my role as a nearpeer mentor kicked off what became a long string of STEM education outreach...now I hope to make a career out of it!" Another reported that "I became much more interested in education, and subsequently chose to pursue a medical education leadership track in medical school." A few narratives also referenced personal growth and respect for education as a discipline. A respondent wrote, "the summer I spent as a near-peer mentor had a profound effect on my love of learn- ing and teaching," while another recorded that it "taught me an immense amount of the importance of mentorship." In addition to the examples above, the respondents reported contributing their time to being STEM tutors, school volunteers, and museum docents, coaches for engineering competitions, science fair judges, and active participants in the education section of their professional societies. One former intern wrote of spending a year teaching basic science to an indigenous population. Thus these former NPMs have engaged in an impressive variety of mentoring opportunities.

In an unexpected result, respondents took time to explain their own values regarding teaching and mentoring (42\%). One wrote: "as a near-peer mentor I was able to incorporate my education and passion for service to commit myself to helping young people in my own community unlock a possible lifelong passion for science and engineering." Another noted: "being a near-peer mentor has unlocked my inner desire to improve the educational system....I see myself being involved in educational reform." These young professionals reported that they "see the importance of early exposure to scientific fields" and that internships "make a difference in their [students'] love of learning." In a longer plea for education reform, one wrote that "it is important to provide accessible science and technology education... as the world advances, a citizenry with a strong understanding of fundamental scientific concepts is important."

In addition to reporting their contributions to outreach and advocating for internships, the former NPMs also discussed their continued passion for the sciences. They provided 44 examples of how the internship strengthened their commitment and continued persistence in STEM careers. As detailed above, they wrote of gaining scientific and professional skills as well as self-confidence. This combination of teaching and mentoring led to additional opportunities. "Having to teach what I knew to others required that I deepen my understanding of these topics which ultimately lead to a deeper interest and love of the sciences," wrote one respondent in speaking of how the internship strengthened academic skills. While those in school wrote of their aspirations such as "pursuing anesthesiology as a career" or a desire to "pursue scientific lab research," those currently employed wrote of their careers. From being a "project engineer" to "medical doctor" to "water quality modeler" and finally a mother arguing for more elementary science resources, the former NPMs were dedicated to the sciences. Despite the one respondent who expressed less interest in outreach, one hundred percent (40) of the respondents reported they would accept an outreach opportunity to share their scientific enthusiasm.

\section{DISCUSSION}

The results of the first research question conclusively showed that the NPMs who responded to the survey per- 
sisted in STEM disciplines. While previous studies of URE outcomes have primarily focused on the undergraduates' aspirations, this study showed aspirations can and do ripen into careers. Nineteen of the 20 former NPMs who were not students at the time of the survey were in STEM-related careers. The remaining 20 NPMs were currently in STEM degree programs. Notably, the NPMs persistence in STEM was consistent across every year of the 12-year study.

Our results complement previously published findings about the profound effect UREs and mentoring have on the aspirations of individuals who have limited access to role models in the sciences, such as those from underrepresented and/or underserved groups (Fuchs et al., 2016; Salto et al., 2014). As noted in the program overview, the NPMs were recruited from diverse communities, and were compensated with competitive stipends to make this internship accessible for people from diverse economic backgrounds. During the selection process every effort was made to achieve a balanced representation of ethnic and racial backgrounds from local communities and to avoid gender bias. In this study, $32 \%$ of the respondents identified with either a racial or ethnic population that is underrepresented in STEM careers (Pentyala et al., 2016) and approximately $75 \%$ of the respondents were female. The complexity and length of their narratives would suggest that the experiences of learning, and teaching, were mutually reinforcing. The interns learned to form diverse, multidisciplinary teams in an environment of mutual respect and shared responsibilities. Our data indicate that this blended internship reinforced aspirations that evolved into STEM pathways for all respondents, including those from populations traditionally underrepresented in STEM careers. Given the difficulty of retaining people from under-represented populations in STEM (Lane, 2016), the success of the NPM experience is notable. The respondents from underrepresented ethnic groups in STEM credited the NPM experience with being pivotal to their persistence in the sciences and engineering.

Of particular relevance to the NPMs was the degree to which teaching and mentoring skills continued to be important in their educational and career paths. While the NPMs reported many skills as influential in obtaining a subsequent teaching opportunity, research internship, or employment, it was the mentoring experience that was referenced when speaking of their success. Many NPMs stressed the weekly repetition of teaching and the constant awareness of mentoring responsibilities as opening doors to subsequent opportunities. They had learned to be responsible for providing the best possible resources and lessons to their students. They wrote of being motivated to do additional reading, revise lessons, complete reflections, learn library skills, and to practice creative problem solving. One NPM summarized this eclectic mix of assignments as "the ability to work in an environment such as WRAIR as a mentor gave me exposure to working with youth who were interested in STEM, to turning office and lab spaces into a classroom, and to working with other young engineers."

Many former NPMs emphasized the importance of teaching experience as an undergraduate. This parallels a current trend in hiring science faculty with education specialties (Addy et al. 2015; Bush et al., 2011). In addition, the evolving emphasis on course-based undergraduate research experiences (CURE) (Corwin et al., 2015) has resulted in research faculty being tasked with implementing and developing novel courses that merge into laboratory experiences (Shortlidge et al., 2015). In retrospect, the NPM-URE prepared the interns for a shifting research environment in which effective pedagogy is becoming more valued and supported.

This conclusion is buttressed by the NPM comments about the benefits of mentoring experience when applying for undergraduate and teaching assistantships and the financial support these positions offer. It also gave them a unique experience to include on their applications and a discussion topic in interviews. As stated by one NPM, "It is quite an experience to lead a group of 15-20 high school students through complex experiments. I was asked about the experience during every one of my medical school interviews. Every interviewer commented on what a great program it was."

Finally, these former mentors felt better prepared as they transitioned into careers in which outreach, team building and communication skills were listed in the job description. With mentoring experience the interns were comfortable explaining their ideas to peers, graduate directors or lay audiences. It was the range of knowledge gained while being mentored and then practicing that knowledge while mentoring that combined to prepare them for their own professional experiences. Other non-STEM, but valuable, learning gains from the NPM-URE included better time management, leadership skills and the ability to network. Undergraduate persistence in the sciences is strengthened when interns are given the training and the responsibilities of mentoring.

Throughout the narrative, the NPMs credited their experiences with helping to shape their attitudes, beliefs, and decisions about STEM careers, education, and outreach. It confirmed their aspirations but also instilled in them the desire to share their love and knowledge of science with others. As shown from the statements of the NPMs reported above, they were both excited and gratified to see their mentees begin to understand the scientific concepts they taught. This excitement carried over into subsequent activities, as several of the NPMs chose teaching or education for all or part of their education or careers. In addition to teaching in formal settings, many of the former NPMs engaged in informal science education activities, such as judging in science fairs, serving as volunteers in local schools and coaching in engineering competitions. Perhaps even more important was 
their commitment to science education generally and their desire to improve the educational system. Thus, the NPM helped create a cadre of STEM professionals who not only persisted in STEM but also retained an active commitment to helping younger students gain a love and an appreciation for science.

\section{IMPLICATIONS FOR PRACTICE}

The results of this study have implications for professional practice. They show that giving undergraduates combined teaching and mentoring responsibilities enhances their research skills and gives undergraduates experiences and confidence they otherwise would not have had an opportunity to develop. While this model is primarily designed for summer programs, we hope that university administrators and teachers could create opportunities for undergraduates to mentor slightly younger students to encourage and develop persistence in STEM disciplines. Allowing undergraduate students the experience to be both learners and mentors will give them a perspective on STEM they could achieve in no other way. As the results of this study have shown, this opportunity will encourage students into long-term engagement with STEM as professionals and mentors.

\section{AUTHOR INFORMATION Corresponding Author}

Margery K. Anderson, Department of Science Education and Strategic Communications, Walter Reed Army Institute of Research. 503 Robert Grant Avenue, Silver Spring, MD 20910. (301) 319-3022. (301) 319-3194 (fax). margery.d.anderson2.ctr@mail.mil

\section{Author Contributions}

The manuscript was written through contributions of all authors. All authors have given approval to the final version of the manuscript.

\section{Disclaimer}

The material has been reviewed by the Walter Reed Army Institute of Research. There is no objection to its presentation and/or publication. The opinions or assertions contained herein are the private views of the authors, and are not to be construed as official, or as reflecting the true views of the Department of the Army or the Department of Defense. AR $70-25$

\section{FUNDING SOURCES}

The current study was supported by the following grants: NIH R25 RR015629, NIH R25 RR018619, NIH R25 RR023322, and NIH R25 OD016515.

\section{ACKNOWLEDGMENTS}

Thank you to the many scientists, teachers, students and mentors who have made this program possible.

\section{ABBREVIATIONS}

URE: Undergraduate research experiences; STEM: science, technology, engineering, and math; NIH-SEPA: National Institutes of Health through Science Education Partnership Awards; WRAIR: Walter Reed Army Institute of Research; GEMS: Gains in the Education of Mathematics and Science; NPM: Near-peer mentor.

\section{REFERENCES}

Adedokun, O., Bessenbacher, A., Parker, L., Kirkham, L., and Burgess, W. (2013). Research skills and STEM undergraduate research students' aspirations for research careers: Mediating effects of research self-efficacy. Journal of Research in Science Teaching 50(8), 940-951. doi: 10.1002/tea.21102

Addy, T. M., Simmons, P., Gardner, G. E., and Albert, J. (2015). A New" Class" of undergraduate professors: Examining teaching beliefs and practices of science faculty with education specialties. Journal of College Science Teaching, 44(3), 91-99.

Allen, T. (2007). Mentoring relationships from the perspective of the mentor. In Ragins, B. \& Kram, K. (Eds.), The Handbook of Mentoring at Work: Theory, Research and Practice (pp. 123-147). Thousand Oaks, CA: Sage.

American Association for Public Opinion Research (2015). Standard definitions: Final dispositions of case codes and outcome rates for surveys (8th ed.). Oakbrook Terrace, IL: American Association of Public Opinion Research.

Anderson, M. K., Tenenebaum, L. S., Ramadorai, S. B., and Yourick, D. L. (2015). Near-peer mentor model: Synergy within mentoring. Mentoring and Tutoring: Partnerships in Learning, 23(2), 116-132. doi:10.1080/13611267.2015.10 49017

ATLAS.ti Scientific Software Development GmbH, 2017. ATLAS.ti. Berlin.

Bascom-Slack, E., Arnold, A., and Strobel, S. (2012). Student-directed discovery of the plant microbiome and its products. Science 338(6106), 485-486. doi:10.1126/science. 1215227

Bliss, T. J., Dillman, A., Russell, R., Anderson, M., Yourick, D., Jett, M., and Adams, B. J. (2007). Nematodes: Model organism in high school biology: An inquiry-based laboratory involving insecticidal nematodes teaches students about experimental design. The Science Teacher, 34.

Bogdan, R., and Biklen, S. (5th Ed.) (2007). Qualitative research for education: An introduction to theory and practice. USA: (Allyn and Bacon). 
Bush, S. D., Pelaez, N. J., Rudd, J. A., Stevens, M. T., Tanner, K. D., and Williams, K. S. (2011). Investigation of science faculty with education specialties within the largest university system in the United States. CBE-Life Sciences Education, 10(1), 25-42.

Carraccio, C., Englander, R., Gilhooly, J., Mink, R., Hofkosh, D., Barone, M. A., and Holmboe, E. S. (2017). Building a framework of entrustable professional activities, supported by competencies and milestones, to bridge the educational continuum. Academic Medicine, 92(3), 324-330.

Corwin, L. A., Graham, M. J., and Dolan, E. L. (2015). Modeling course-based undergraduate research experiences: An agenda for future research and evaluation. CBE-Life Sciences Education, 14(1), es1.

Couper, N. P. and Bosnjak, M. (2010). Internet surveys. In Marsden, P. V. and Wright, J. D. Handbook of survey research. (2nd ed., pp. 527-550). Bingley, UK: Emerald Group Publishing Limited.

Crisp, G., Baker, V. L., Griffin, K. A., Lunsford, L. G., and Pifer, M. J. (2017) Special Issue: Mentoring Undergraduate Students, ASHE Higher Education Report, v43 n1 p1-117.

Curiale, J. L. (2010). America's new glass ceiling: unpaid internships, the Fair Labor Standards Act, and the urgent need for change. Hastings Law Journal, 61, 1531.

Dolan, E. and Johnson, D. (2009). Toward a holistic view of undergraduate research experiences: An exploratory study of impact on graduate/postdoctoral mentors. Journal of Science Education and Technology, 18, 487-500. doi:10.1007/ s10956-009-9165-3

Eagan, Jr., M., Hurtado, S., Chang, M., Garcia, G., Herrera, F., and Garibay, J. (2013). Making a difference in science education: The impact of undergraduate research programs. American Educational Research Journal 50(4), 683-713. doi: $10.3102 / 0002831213482038$

Fuchs, J., Kouyate, A., Kroboth, L., and McFarland, W. (2016). Growing the pipeline of diverse HIV investigators: The impact of mentored research experiences to engage underrepresented minority students. AIDS Behavior 20, S249S257. doi: 10.1007/s10461-016-1392-z

Ghee, M., Keels, M., Collins, D., Neal-Spence, C, and Baker, E. (2016). Fine-tuning summer research programs to promote underrepresented students' persistence in the STEM pathway. CBE-Life Sciences Education 16 (September). doi:10.1187/cbe.16-01-0046

Hanauer, D. and Dolan, E. (2014). The project ownership survey: Measuring differences in scientific inquiry experiences. CBE-Life Sciences Education, 13 (Spring), 149-158. doi:10.1187/cbe.13-06-0123

Hanauer, D., Frederick, J., Fotinakes, B., and Strobel, S. (2012). Linguistic analysis of project ownership for undergraduate research experiences. CBE-Life Sciences Education, 11 (Winter), 378 - 384. doi:10.1187/cbe.12-04-0043

Hayward, C., Laursen, S. and Thiry, H. (2017). Why work with undergraduate researchers? Difference in research advisors' motivations and outcomes by career stage. CBE-Life Sciences Education, 16 (March). doi:10.1187/cbe.16-07-0229
Hazari, Z., Potvin, G., Cribbs, J. D., Godwin, A., Scott, T. D., and Klotz, L. (2017). Interest in STEM is contagious for students in biology, chemistry, and physics classes. Science Advances, 3(8), e1700046. doi:10.1126/sciadv.1700046

Hamos, J. E., Bergin, K. B., Maki, D. P., Perez, L. C., Prival, J. T., Rainey, D. Y., Rowell, G.H., and VanderPutten, E. (2009). Opening the Classroom Door: Professional Learning Communities in the Math and Science Partnership Program. Science Educator, 18(2), 14-24.

Jett, M., Anderson, M.K., and Yourick, D. L. (2005). Near peer mentoring: A step-wise means of engaging young students in science. FASEB Journal, 19(5), A1396-A1396.

Keusch, F. (2012). How to increase response rates in list-based survey samples. Social Science Computer Review 30(3), 380-388. doi:10.1177/0894439311409709

Kalton, G. 1983. Introduction to Survey Sampling. Newbury Park, CA: Sage.

Laursen, S., Hunter, A-B., Seymour, E., Thiry, H, and Melton, G. (2010). Undergraduate research in the sciences: Engaging students in real science. San Francisco: Jossey-Bass.

Lane, T. B. (2016). Beyond Academic and Social Integration: Understanding the Impact of a STEM Enrichment Program on the Retention and Degree Attainment of Underrepresented Students. CBE-Life Sciences Education, 15(3), ar39.

Linn, M., Palmer, E., Baranger, A., Gerard, E., and Stone, E. (2015). Undergraduate research experiences: Impacts and opportunities. Science 347(6222), 1261757. doi:10.1126/ science. 1261757

Maio, G., and Haddock, G. (2014). The psychology of attitudes and attitude change. USA. Sage.

Merriam, S., Caffarella, R., and Baumgartner, L. (2007). Learning in adulthood: A comprehensive guide. San Francisco: Jossey-Bass.

Morales, A. L., Rowton, E., Anderson, M., and Yourick, D. (2017). What's inside a termite's gut? The Science Teacher, 84(7), 47

National Academies of Sciences, Engineering, and Medicine. (2017). Undergraduate research experiences for STEM Students: Successes, challenges, and opportunities. Washington, DC: The National Academies Press. doi: $10.17226 / 24622$

Nelson, K. L., and Cutucache, C. E. (2017). How do former undergraduate mentors evaluate their mentoring experience 3-years post-mentoring: A phenomenological study. The Qualitative Report, 22(7), 2033-2047. Retrieved from http://nsuworks.nova.edu/tqr/vol22/iss 7/19

NCSS, LLC. (2016). NCSS 11 Statistical Software. Kaysville, Utah, USA, ncss.com/software/ncss.

Pentyala, S., Dilger, J., and Rebecchi, M. (2016). Minority students and STEM careers: Will mentoring help? Journal of Health Education Research and Development, 1-5.

Petrovčič, A., Petrič, G., and Manfreda, L. (2016). The effect of email invitation elements on response rate in a web survey within an online community. Computers in Human Behavior 56, 320-329. doi:/10.1016/j.chb.2015.11.025 
Reid, J., Smith, E., Iamsuk, N., and Miller,J. (2016). Balancing the equation: Mentoring first-year female STEM students at a regional university. International Journal of Innovation in Science and Mathematics Education, 24(4), 18-30.

Russell, S., Hancock, M. and McCullough. (2007). Benefits of undergraduate research experiences. Science 316(5824), $548-549$.

Saldaña, J. (2015). The coding manual for qualitative researchers. Sage.

Salto, L., Riggs, M,L, Delgado, D., Casiano, C., and De Leon, M. (2014). Underrepresented minority high school and college students report STEM Pipeline sustaining gains after participating in the Loma Linda University summer health disparities research program. PLoS ONE 9(9): e108497. doi:10.1371/journal.pone. 0108497

Shortlidge, E. E., Bangera, G., and Brownell, S. E. (2015). Faculty perspectives on developing and teaching course-based undergraduate research experiences. BioScience, 66(1), $54-62$.

Stirling, A., Kerr, G., MacPherson, E., Banwell, J., Bandealy, A., and Battaglia, A. (2017). Do postsecondary internships address the four learning modes of experiential learning theory? An exploration through document analysis. Canadian Journal of Higher Education 47(1), 27-48.

Tenenbaum, L. S., Anderson, M. K., Jett, M., and Yourick, D. L. (2014). An innovative near-peer mentoring model for undergraduate and secondary students: STEM focus. Innovative Higher Education,(5)375-385. doi:10.1007/s10755014-9286-3

Tenenbaum, L.S., Anderson, M.K., Ramadorai, S.B., and Yourick, D.L. (2017). Engaging high school students in the sciences through hands-on learning and near-peer mentorship: Students' experience in their own words. Journal of STEM Education: Innovations and Research, (18)3, 30-37.

U.S. Army Educational Outreach Programs (2017). Summative Evaluation Report. Available at, https://www.usaeop.com/ about/our-impact/

Wang, X. (2013). Why students choose STEM majors: Motivation, high school learning, and postsecondary context of support. American Educational Research Journal, 50(5), 1081-1121.

Weston, T., and Laursen, S. (2015). The undergraduate research student self-assessment (URSSA): Validation for use in program evaluation. CBE-Life Sciences Education, 14 (Fall), 1-10. doi:10.1187/cbe.14-11-0206

Wu, W., Martin, B. C., and Ni, C. (2017). A systematic review of competency-based education effort in the health professions: Seeking order out of chaos. In Handbook of Research on Competency-Based Education in University Settings (pp. 352-378). IGI Global. 